\title{
Effect of Angle Of Attack on Stiffness Derivative of an Oscillating Supersonic Delta Wing with Curved Leading Edges
}

\author{
Asha Crasta ${ }^{1}$ and S. A. Khan ${ }^{2}$ \\ 1Sr. Assistant Professor, Mangalore Institute of Technology and Engineering, Moodbidri, Karnataka, India. \\ 2 Principal, Z. H. College of Engineering \& Technology, AMU, Aligarh, UP, India
}

\begin{abstract}
In the Present paper effect of angle of incidence on Stiffness derivative of a delta wing with Curved leading edges for attached shock case in Supersonic Flow has been studied. A Strip theory is used in which strips at different span wise location are independent of each other. This combines with similitude to give a piston theory which gives closed form solutions for stiffness derivatives at low supersonic to high supersonic Mach numbers. From the results it is seen that with the increase in the Mach number, there is a continuous decrease in the magnitude of stiffness derivatives for all the Mach number tested, however, the magnitude of decrement for different inertia level will differ. It is seen that with the increase in the angle of attack the stiffness derivative increases linearly, nevertheless, this linear behavior limit themselves for different Mach numbers. For Mach number $M=2$, this limiting value of validity is fifteen degrees, for Mach $2.5 \& 3$, it is twenty five degrees, whereas, for Mach 3.5 \& 4 it becomes thirty five degrees, when these stability derivatives were considered at various pivot positions; namely at $h=0.0,0.4,0.6$, and 1.0. After scanning the results it was observed that with the shift of the pivot position from the leading edge to the trailing edge, the magnitude of stiffness and the damping derivatives continue to decrease progressively. Results have been obtained for supersonic flow of perfect gases over a wide range of angle of attack and Mach number. The effect of real gas, leading edge bluntness of the wing, shock motion, and secondary wave reflections are neglected.
\end{abstract}

Keywords: angle of attack, delta wing, Supersonic flow, pitching derivatives, Piston theory

\section{Introduction}

The analysis of hypersonic and supersonic flow over flat deltas (with straight leading edge and curved leading edge) over a wide incidence range is of current interest since the desire for high speed, maneuverability and efficiency has been dominating the evolution of high performance military aircrafts. The knowledge of aerodynamic load and stability for such types is a need for calculating simple but reasonably accurate methods for parametric calculations facilitating the design process. The computation of dynamic stability for these shapes at high incidence which is likely to occur during the course of reentry or maneuver is of current interest. Usually the shock waves are very strong when descending and they can either be detached or attached.

The theories for steady delta wings in supersonic/hypersonic flow with shock wave attached were given by Pike [1] and Hui [2]. Carrier [3] and Hui [4] gave exact solutions for 2-D flow in the case of an oscillating wedge and for an oscillating flat plate were given by Hui [5], which is valid uniformly for all supersonic Mach numbers and wedge angles or angles of attack with attached shock wave. Hui [5] also calculated pressure on the compression side of a flat delta.

The importance of dynamic stability at large incidence during re-entry or maneuver has been pointed out by Orlik-Ruckemann [6]. The shock attached relatively high aspect ratio delta is often preferred for its high lift to drag ratio. Hui and Hemdan [7] have studied the unsteady shock detached case in the context of thin shock layer theory. Liu and Hui [8] have extended Hui's [5] theory to a shock attached delta wing in pitch. Light hill [9] has developed a "Piston Theory" for oscillating airfoils at high Mach numbers. A parameter $\delta$ is introduced, which is a measure of maximum inclination angle of Mach wave in the flow field. It is assumed that $\mathrm{M}_{\infty} \delta$ is less than or equal to unity (i.e. $\left.\mathrm{M}_{\infty} \delta \leq 1\right)$ and is of the order of maximum deflection of a streamline. Light hill [9] likened the 2-D unsteady problem to that of a gas flow in a tube driven by a piston and termed it "Piston Analogy".

Ghosh [10] has developed a large incidence 2-D hypersonic similitude and piston theory. It includes Light hill's [9] and Mile's [11] piston theories. Ghosh and Mistry [12] have applied this theory of order of $\phi^{2}$ where $\phi$ is the angle between the attached shock and the plane approximating the windward surface. For a plane surface, $\phi$ is the angle between the shock and the body. The only additional restriction compared to small disturbance theory is that the Mach number downstream of the bow shock is not less than 2.5.

Ghosh [13] has obtained a similitude and two similarity parameters for shock attached oscillating delta wings at large incidence. Crasta and Khan have extended the Ghosh similitude to Hypersonic/supersonic flows past a planar wedge [14] and [18] and Non planar wedge [20], [21], and [22]. Crasta and Khan have obtained stability derivatives in pitch and roll of a delta wing with straight leading edge [23] and [24] and curved leading 
edges for supersonic flows [15] and Hypersonic flows [16]. Crasta and Khan have studied the effect of angle of incidence on pitching derivatives and roll of a damping derivative of a delta wing with curved leading edges for an attached shock case [17] and [27]. Further in all cases stability derivatives in Newtonian limit have been calculated by Crasta and Khan [19], [25], and [26]. In the present analysis the effect of angle of attack on the stiffness derivative for supersonic flows with curved leading edge has been studied and results are obtained are shown in the section to follow.

\section{Analysis:}

In the present analysis Ghosh's (1981) unified supersonic/hypersonic similitude has been used in combination with a strip theory for a supersonic delta wing whose leading edge is curved. A thin strip of the wing, parallel to the centerline, can be considered independent of the $\mathrm{Z}$ dimension when the velocity component along the $\mathrm{Z}$ direction is small. This has been discussed by Ghosh's(1984). The strip theory combined with Ghosh's large incidence similitude leads to the piston analogy and pressure $\mathrm{P}$ on the surface can be directly related to equivalent piston mach no. $\mathrm{M}_{\mathrm{P}}$. In this case both $\mathrm{M}_{\mathrm{P}}$ and flow deflections are permitted to be large. Hence light hill piston theory cannot be used but Ghosh's piston theory will be applicable.

$\frac{\mathrm{P}}{\mathrm{P} \infty}=1+\mathrm{AM}_{\mathrm{P}}^{2}+\mathrm{A} \mathrm{M}_{\mathrm{P}}\left(\mathrm{B}+\mathrm{M}_{\mathrm{P}}^{2}\right)^{1 / 2}$, where $p_{\infty}$ is free steampressure

Since strips at different span wise location are assumed independent of each other, the strip can be considered as a flat plate at an angle of attack. The angle of incidence is same as that of the wing. Angle $\phi$ is the angle between the shock and the strip. A piston theory which has been used in eqn.(1) has been extended to supersonic flow. The Expression is given below

$$
\frac{p}{p_{\infty}}=1+A\left(\frac{M_{p}}{\cos \phi}\right)^{2}+A\left(\frac{M_{p}}{\cos \phi}\right)\left(B+\left(\frac{M_{p}}{\cos \phi}\right)^{2}\right)^{\frac{1}{2}}
$$

Where $p_{\infty}$ is free stream pressure, $A=\frac{(\gamma+1)}{4}, B=\left(4 /(\gamma+1)^{2}\right), \gamma$ is the specific heat ratio and $M_{p}=$ the local piston Mach number normal to the wing surface.

\section{Pitching moment derivatives}

Let the mean incidence be $\alpha_{0}$ for the wing oscillating in pitch with small frequency and amplitude about an axis $x_{0}$. The piston velocity and hence pressure on the windward surface remains constant on a span wise strip of length $2 \mathrm{z}$ at $\mathrm{x}$. The pressure on the lee surface is assumed Zero. Therefore the nose up moment is

$$
m=-2 \int_{0}^{c} p \cdot z\left(x-x_{0}\right) d x
$$

\section{Stiffness Derivative}

The stiffness derivative is non-dimensionalized by dividing with the product of dynamic pressure, wing area and chord length.

$$
\therefore-C_{m_{\alpha}}=\frac{2}{\rho_{\infty} U_{\infty}^{2} C^{3} \cot \varepsilon}\left(-\frac{\partial m}{\partial \alpha}\right)_{\substack{\alpha=\alpha_{0} \\ q=0}}
$$

The local piston Mach number normal to the wing surface is given by

$$
M_{p}=M_{\infty} \sin \alpha+\frac{q}{a_{\infty}}\left(x-x_{o}\right)
$$

And the equation of the curved leading edge is given by

$$
Z=x \cot \in-a_{F} \sin \left(\frac{2 \pi x}{c}\right)-a_{H} \sin \left(\frac{\pi x}{c}\right)
$$

We Define

$$
S_{1}{ }^{1}=\frac{M_{\infty} \sin \alpha_{o}}{\cos \phi}
$$

From Eq2-6 


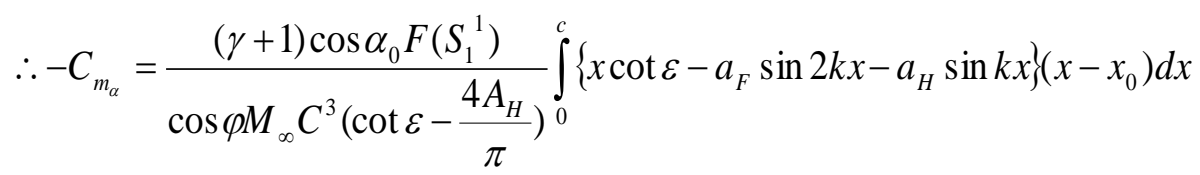

Multiplying the numerator and the denominator by $2 \sin \alpha_{o} / \cos \phi$,

$$
-C_{m_{\alpha}}=\frac{2(\gamma+1) \sin \alpha_{o} \cos \alpha_{o} F\left(S_{1}{ }_{1}\right)}{2 S^{1}{ }_{1} \cos ^{2} \phi C^{3}\left(\cot \varepsilon-\frac{4 A_{H}}{\pi}\right)} \int_{0}^{c}\left\{x \cot \varepsilon-a_{F} \sin 2 k x-a_{H} \sin k x\right\}\left(x-x_{0}\right) d x
$$

We define $\mathrm{f}\left(s_{1}^{1}\right)=\frac{(\gamma+1)}{2 S_{1}^{1}} F\left(S_{1}^{1}\right)$

$$
-C_{m_{\alpha}}=\frac{2 \sin \alpha_{0} \cos \alpha_{0} F\left(S_{1}{ }_{1}\right)}{2 S^{1}{ }_{1} \cos ^{2} \phi c^{3}\left(\cot \varepsilon-\frac{4 A_{H}}{\pi}\right)}
$$

The integral in eq.(7) has been evaluated and then we get

$$
-C_{m_{\alpha}}=\frac{\sin \alpha_{O} \cos \alpha_{O} f\left(S_{1}^{1}\right)}{\cos ^{2} \varphi\left(\cot \varepsilon-\frac{4 A_{H}}{\pi}\right)}\left[\left(\frac{2}{3}-h\right) \cot \varepsilon+\frac{1}{\pi}\left\{\frac{A_{F}}{2}+A_{H}(2 h-1)\right\}\right]
$$

Where $f\left(s^{1}{ }_{1}\right)=\frac{(\gamma+1)}{2 s^{1}{ }_{1}} F\left(S_{1}{ }_{1}\right)=\frac{(\gamma+1)}{2 s^{1}{ }_{1}}\left[2 s^{1}{ }_{1}+\left(B+2 s^{1}{ }_{1}{ }^{2}\right) /\left(B+S^{1}{ }_{1}{ }^{2}\right)^{\frac{1}{2}}\right.$

By using above expression, stiffness derivative calculations have been carried out and some of the results have been shown.

\section{Results and Discussions}

The closed form analytical solutions obtained are being discussed here.

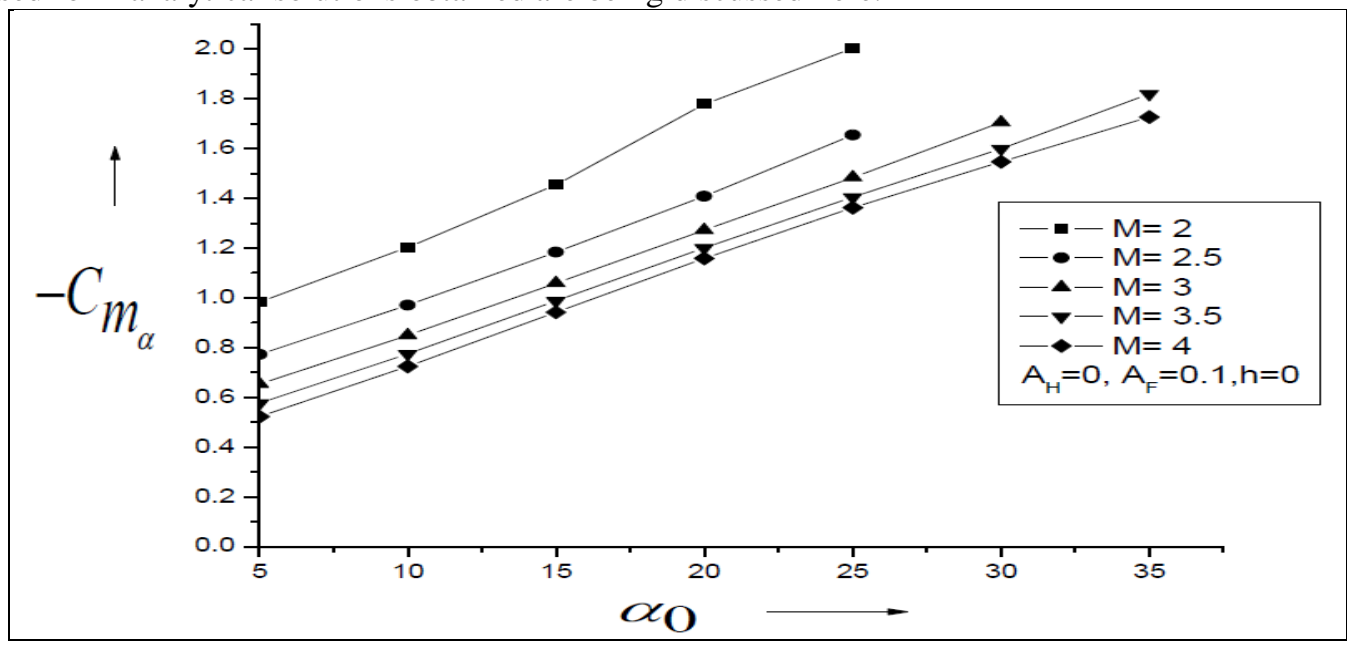

Fig. 1: variation of Stiffness derivative with angle of attack for a full sine wave

Fig. 1 presents the results for stiffness derivatives for full sine with the amplitude of 0.1 and that of half sine wave being zero, with the pivot position $\mathrm{h}=0$. From the results it is seen that there is a continuous decrease in the magnitude of the stiffness derivatives in the range of twenty percent, nineteen percent, eighteen percent and seventeen percent for the Mach numbers in the range 2 to $2.5,2.5$ to 3,3 to 3.5 and 3.5 to 4 . It is seen that with the increase in the angle of attack in stiffness derivative increases linearly, nevertheless, this linear behavior limit themselves in different range for different Mach numbers. For Mach number $\mathrm{M}=2$, this limiting value of validity is fifteen degrees, for Mach $2.5 \& 3$, it is twenty five degrees, whereas, for Mach 3.5 \& 4 it is thirty five degrees. 


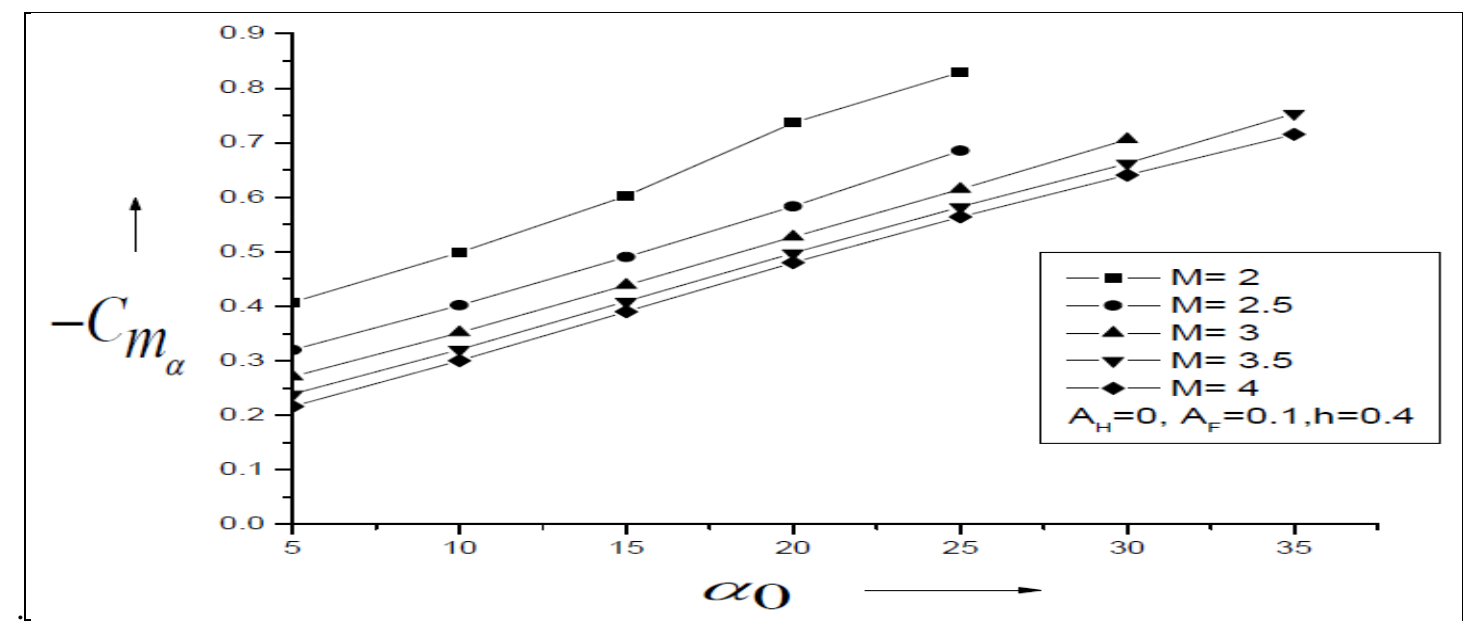

Fig. 2: Variation of Stiffness derivative with angle of attack for a full sine wave

Fig. 2 presents the similar results for the same range of parameters except the pivot position has shifted towards the trailing edge by forty percent from the leading edge resulting in considerable decrease in the overall values of the stiffness derivatives, however; the individual decrease for different Mach number range are twenty four percent, sixteen percent, twelve percent and eleven percent for the Mach number range 2 to $2.5,2.5$ to 3,3 to 3.5 and 3.5 to 4 , respectively.

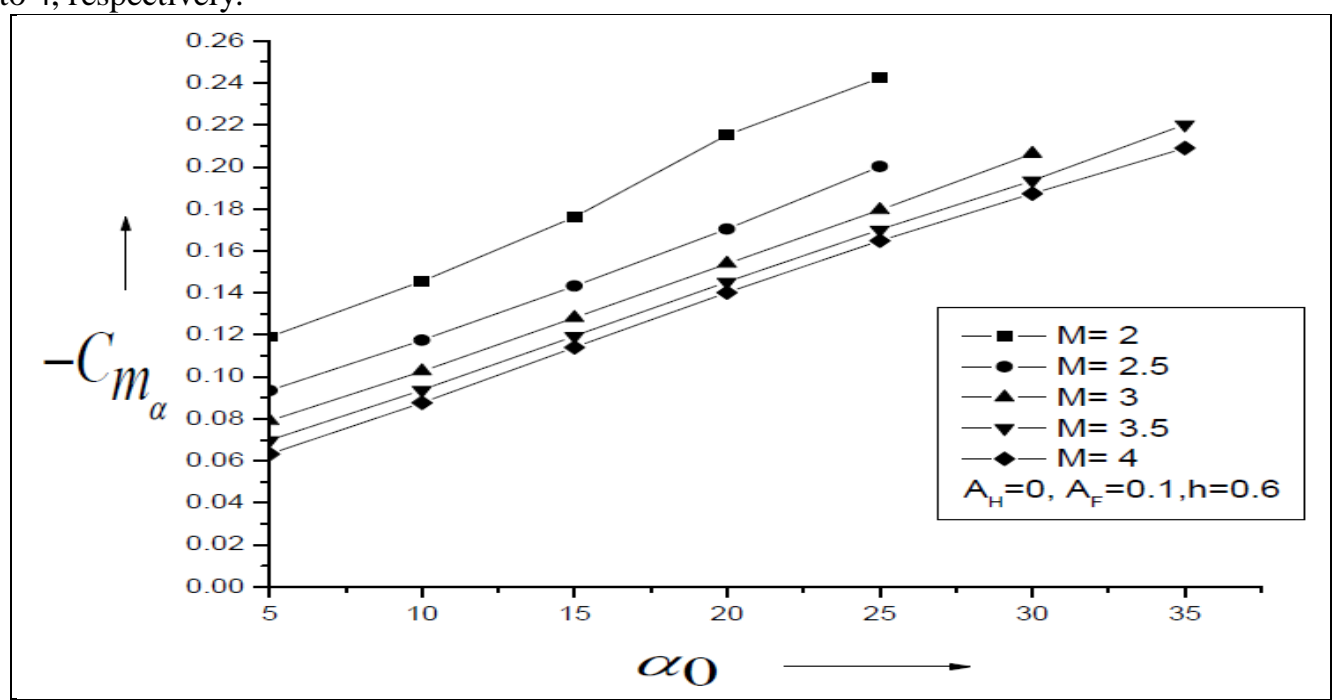

Fig. 3: variation of Stiffness derivative with angle of attack for a full sine wave

Fig. 3 present the results for the case when pivot position as $\mathrm{h}=0.6$, keeping all the parameters same as discussed in Figures 1 and 2. The Percentage decrease in the stiffness derivatives are twenty one percent, sixteen percent, thirteen percent and twelve percent for the Mach number in the range 2 to $2.5,2.5$ to 3,3 to 3.5 and 3.5 to 4 . From the figure 3 it is observed that magnitude of the stiffness derivatives has decreased for all the Mach numbers as compared when it was considered for $\mathrm{h}=0$ or $\mathrm{h}=0.4$. This trend is attributed to the fact that as the pivot position shifts towards the trailing edge it is in the closed proximity of the center of pressure; which, results in decrease of the moment arm of the wing. 


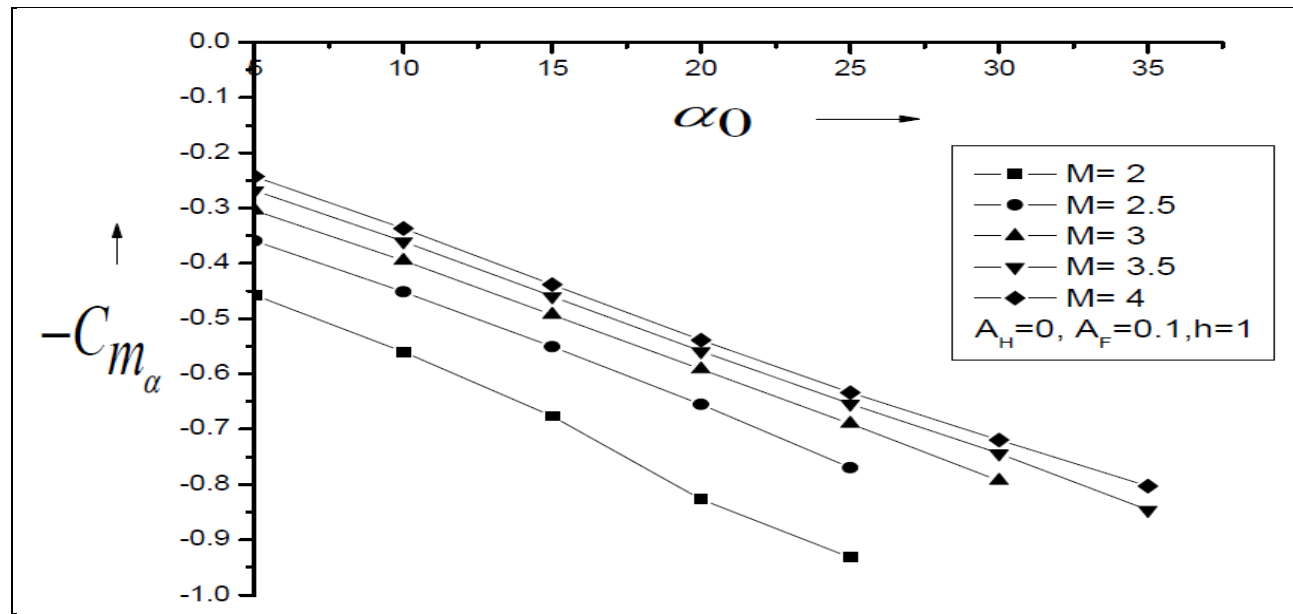

Fig. 4: Variation of Stiffness derivative with angle of attack for a full sine wave

Fig. 4 presents the results of the stiffness derivative for pivot position of $h=1$ having all other parameters same as in the case of figure 1 to 3 . The Percentage decrease in the stiffness derivatives are twenty two percent, fourteen percent, ten percent and seven percent for the Mach number in the range 2 to 2.5, 2.5 to 3 , 3 to 3.5 and 3.5 to 4 . From the figure 4 it is observed that magnitude of the stiffness derivatives has decreased considerably for all the Mach numbers as compared when it was considered for $h=0, h=0.4$ and $h=0.6$. This trend is attributed to the fact that as the pivot position shifts towards the trailing edge and it is behind the center of pressure it results in considerable decrease of the moment arm of the wing.

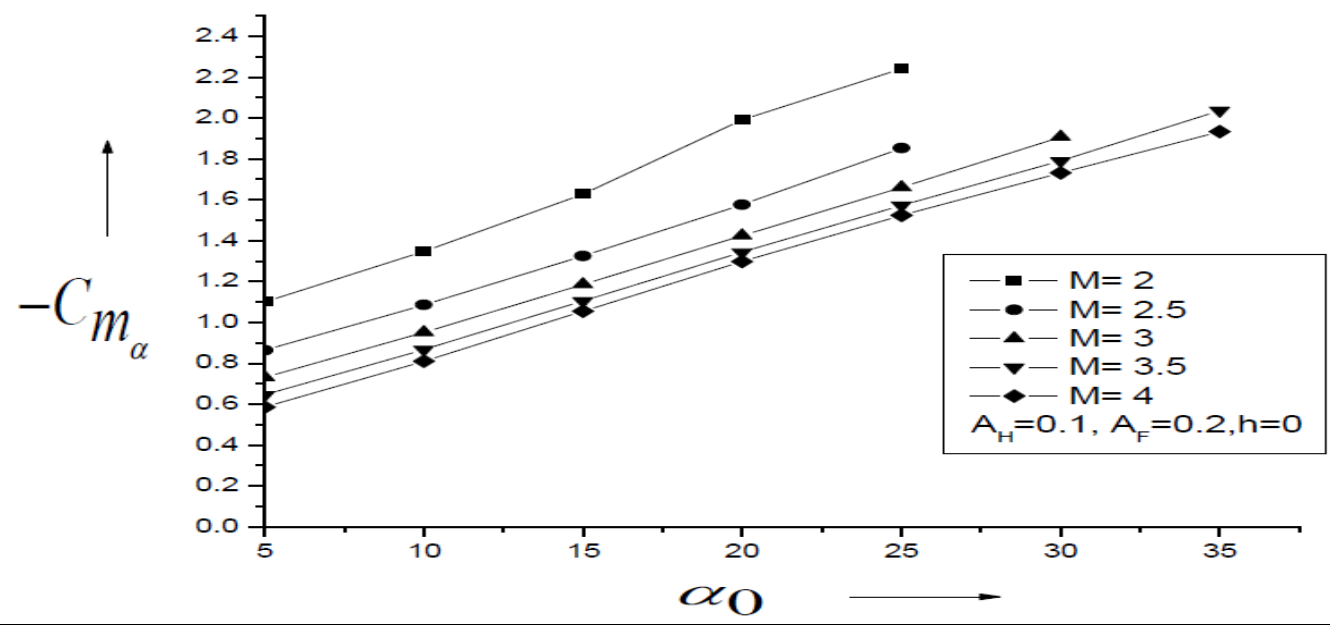

Fig. 5: Variation of Stiffness derivative with angle of attack

Fig. 5 presents the results for stiffness derivatives for full sine and half sine wave with the amplitude being 0.2 and 0.1 with the pivot position $\mathrm{h}=0$. From the results it is seen that in this case also, there is a continuous decrease in the magnitude of the stiffness derivatives in the range of nineteen percent, seventeen percent, fourteen percent and eleven percent for the Mach numbers in the range 2 to $2.5,2.5$ to 3,3 to 3.5 and 3.5 to 4 . It is seen that with the increase in the angle of attack the stiffness derivative increases linearly, nevertheless, this linear behavior limit themselves for different Mach numbers. For Mach number $\mathrm{M}=2$, this limiting value of validity is fifteen degrees, for Mach $2.5 \& 3$, it is twenty five degrees, whereas, for Mach $3.5 \&$ 4 it becomes thirty five degrees. It is also observed that in view of the combined effect of the full sine wave and half sine wave which ultimately results in substantial modification in the plan form area of the wing, this may be the reason for low values of the stiffness derivatives even when the pivot position was chosen to be at the leading edge thereby making $\mathrm{h}=0$. 


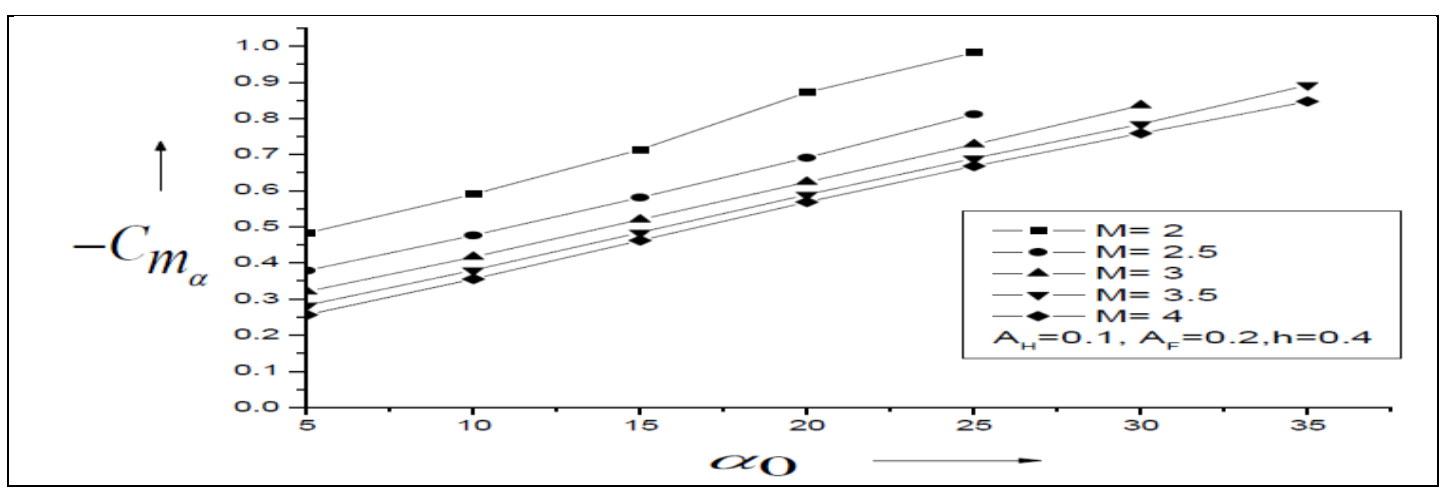

Fig. 6: Variation of stiffness derivative with angle of attack

Fig. 6 presents the results for stiffness derivatives for full sine and half sine wave with the amplitude being 0.2 and 0.1 with the pivot position $h=0.4$. From the results it is seen that they represent similar results as discussed earlier and there is a continuous decrease in the magnitude of the stiffness derivatives in the range of twenty one percent, sixteen percent, thirteen percent and eleven percent for the Mach numbers in the range 2 to $2.5,2.5$ to 3,3 to 3.5 and 3.5 to 4 . It is seen that with the increase in the angle of attack the stiffness derivative increases linearly, nevertheless, this linear behavior limit themselves for different Mach numbers. For Mach number $\mathrm{M}=2$, this limiting value of validity is fifteen degrees, for Mach $2.5 \& 3$, it is twenty five degrees, whereas, for Mach $3.5 \& 4$ it becomes thirty five degrees. The low values of the stiffness derivatives are attributed, due to the combined effect of variation in the wing plan form area and the location of the pivot position which is forty percent from the leading edge.

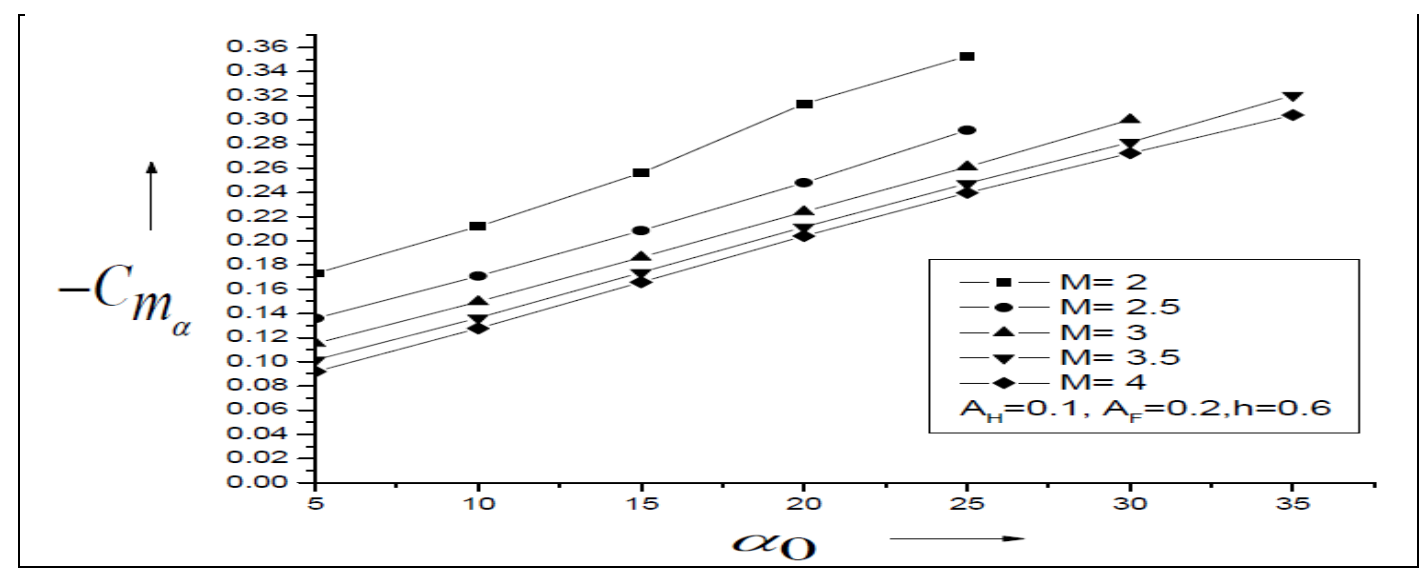

Fig. 7: Variation of Stiffness derivative with angle of attack

Fig. 7 presents the results for stiffness derivatives for full sine and half sine wave with the amplitude being 0.2 and 0.1 with the pivot position $\mathrm{h}=0.6$. From the results it is seen that they represent similar results as discussed earlier and there is a continuous decrease in the magnitude of the stiffness derivatives in the range of twenty percent, seventeen percent, thirteen percent and ten percent for the Mach numbers in the range 2 to $2.5,2.5$ to 3,3 to 3.5 and 3.5 to 4 . It is seen that with the increase in the angle of attack the stiffness derivative increases linearly, nevertheless, this linear behavior limit themselves for different Mach numbers. For Mach number $\mathrm{M}=2$, this limiting value of validity is fifteen degrees, for Mach $2.5 \& 3$, it is twenty five degrees, whereas, for Mach $3.5 \& 4$ it becomes thirty five degrees. The low values of the stiffness derivatives are attributed due to the combined effect of variation in the wing plan form area and the location of the pivot position which is sixty percent from the leading edge; thereby becoming very close to the center of pressure. 


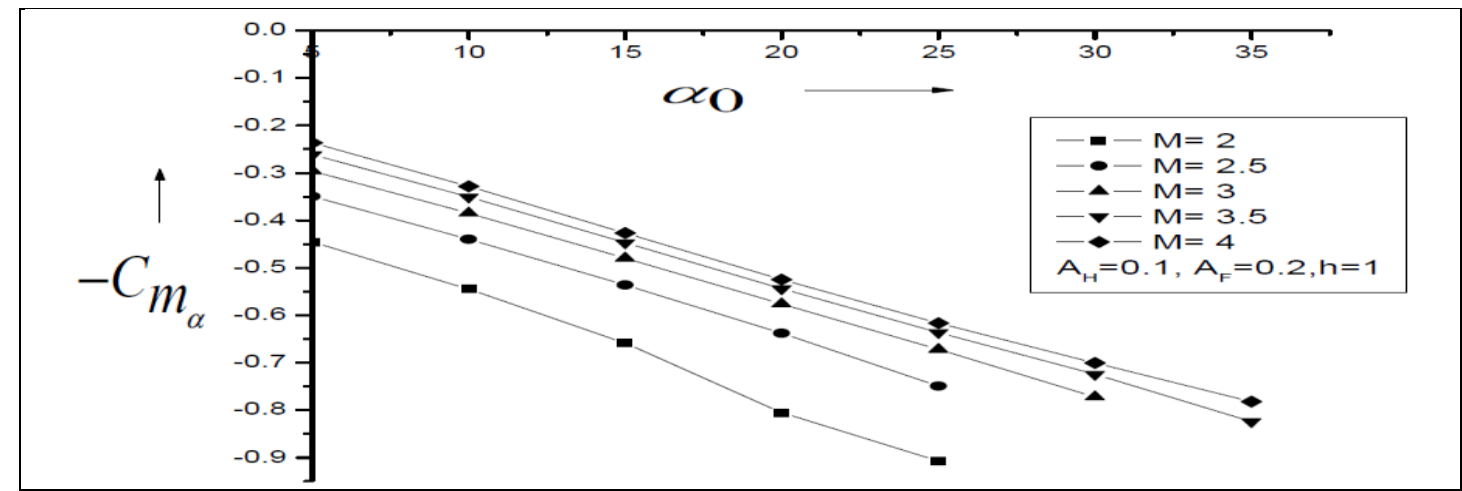

Fig 8: Variation of Stiffness derivative with angle of attack

Fig. 8 presents the results for stiffness derivatives for full sine and half sine wave with the amplitude being 0.2 and 0.1 with the pivot position $\mathrm{h}=1.0$. From the results it is seen that they show similar behavior as discussed earlier and once again, here also; there is a continuous decrease in the magnitude of the stiffness derivatives in the range of twenty two percent, fourteen percent, thirteen percent and twelve percent for the Mach numbers in the range 2 to $2.5,2.5$ to 3,3 to 3.5 and 3.5 to 4 . It is seen that with the increase in the angle of attack the stiffness derivative increases linearly, however, this linear behavior limit themselves for different Mach numbers. For Mach number $M=2$, this limiting value of validity is fifteen degrees, for Mach $2.5 \& 3$, it is twenty five degrees, whereas, for Mach $3.5 \& 4$ it becomes thirty five degrees. The low values of the stiffness derivatives are attributed due to the combined effect of variation in the wing plan form area and the location of the pivot position which is exactly at the trailing edge; which is also behind the center of pressure resulting in negative moment.

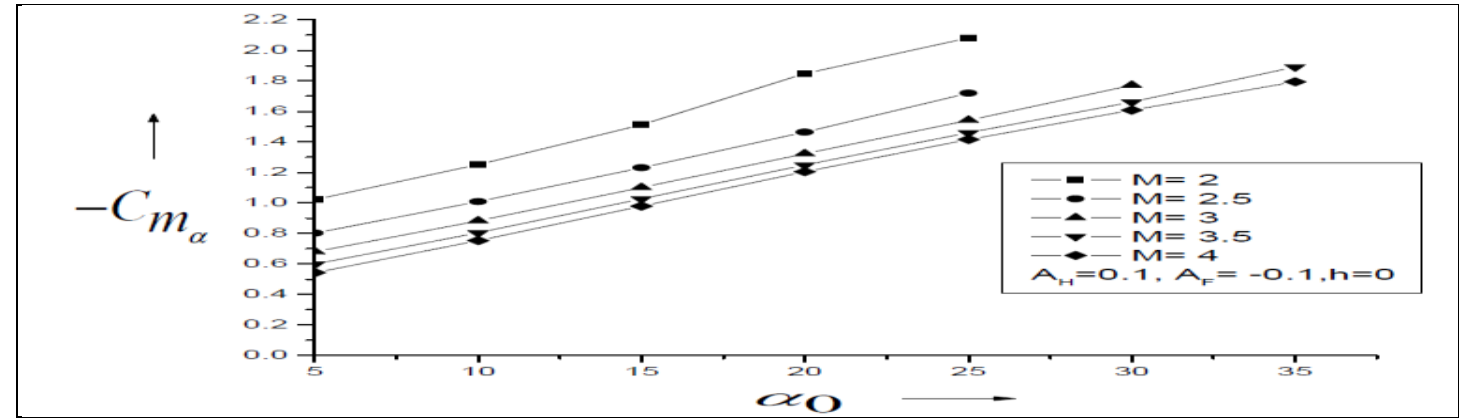

Fig. 9: Variation of Stiffness derivative with angle of attack

Fig. 9 presents the results for stiffness derivatives for full sine and half sine wave with the amplitude being -0.1 and 0.1 with the pivot position $\mathrm{h}=0$. From the results it is seen that they represent similar results and there is a continuous decrease in the magnitude of the stiffness derivatives in the range of twenty four percent, fifteen percent, twelve percent and eight percent for the Mach numbers in the range 2 to 2.5, 2.5 to 3, 3 to 3.5 and 3.5 to 4 . It is seen that with the increase in the angle of attack the stiffness derivative increases linearly, but, this linear behavior limit themselves for different values at different Mach numbers. For Mach number $\mathrm{M}=2$, this limiting value of validity is fifteen degrees, for Mach $2.5 \& 3$, it is twenty five degrees, whereas, for Mach $3.5 \& 4$ it becomes thirty five degrees. The trend in the stiffness derivatives are attributed due to the combined effect of variation in the wing plan form area due to the change in the amplitude of sine waves and the location of the pivot position which is exactly at the leading edge; which is being far away from the center of pressure. 


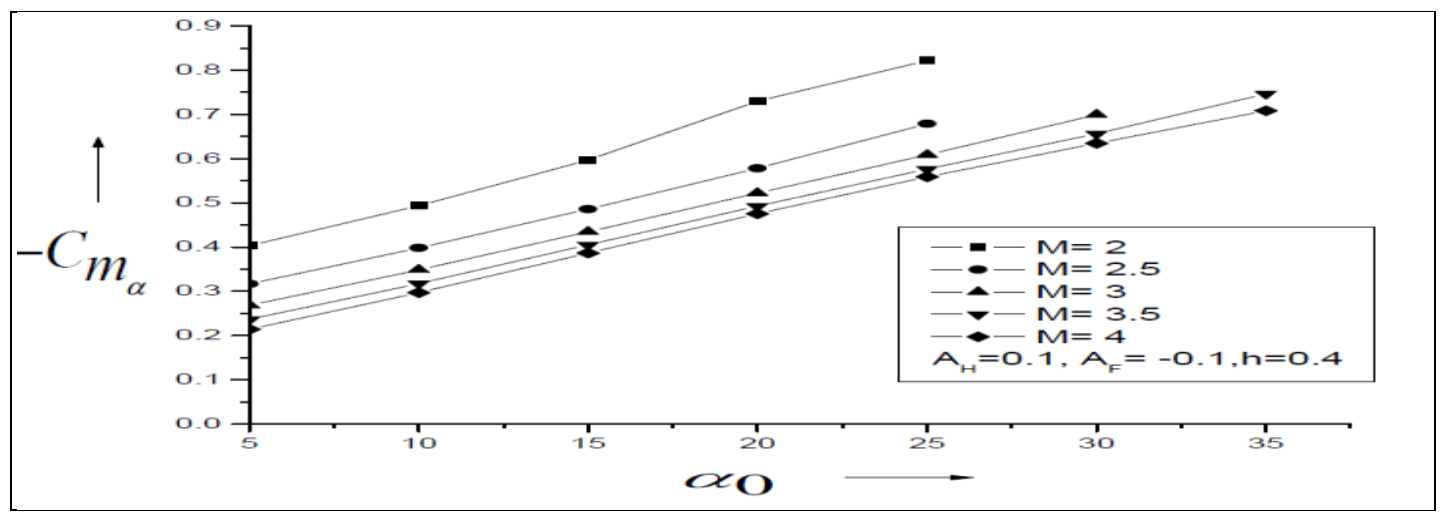

Fig. 10: Variation of Stiffness derivative with angle of attack

Fig. 10 presents the results for stiffness derivatives for full sine and half sine wave with the amplitude being -0.1 and 0.1 with the pivot position $h=0$. 4 . From the results it is seen that they represent similar results and there is a continuous decrement in the magnitude of the stiffness derivatives in the range of twenty two percent, sixteen percent, eleven percent and eight percent for the Mach numbers in the range 2 to $2.5,2.5$ to 3, 3 to 3.5 and 3.5 to 4 . It is seen that with the increase in the angle of attack the stiffness derivative is linear, nevertheless, this linear behavior limit themselves for different Mach numbers. For Mach number $M=2$, this limiting value of validity is fifteen degrees, for Mach $2.5 \& 3$, it is twenty five degrees, whereas, for Mach $3.5 \&$ 4 it becomes thirty five degrees. The change in the values of the stiffness derivatives are attributed due to the combined effect of variation in the wing plan form area due to the change in the amplitude of sine waves and the location of the pivot position which forty percent aft of the leading edge; which is in the close proximity of the center of pressure.

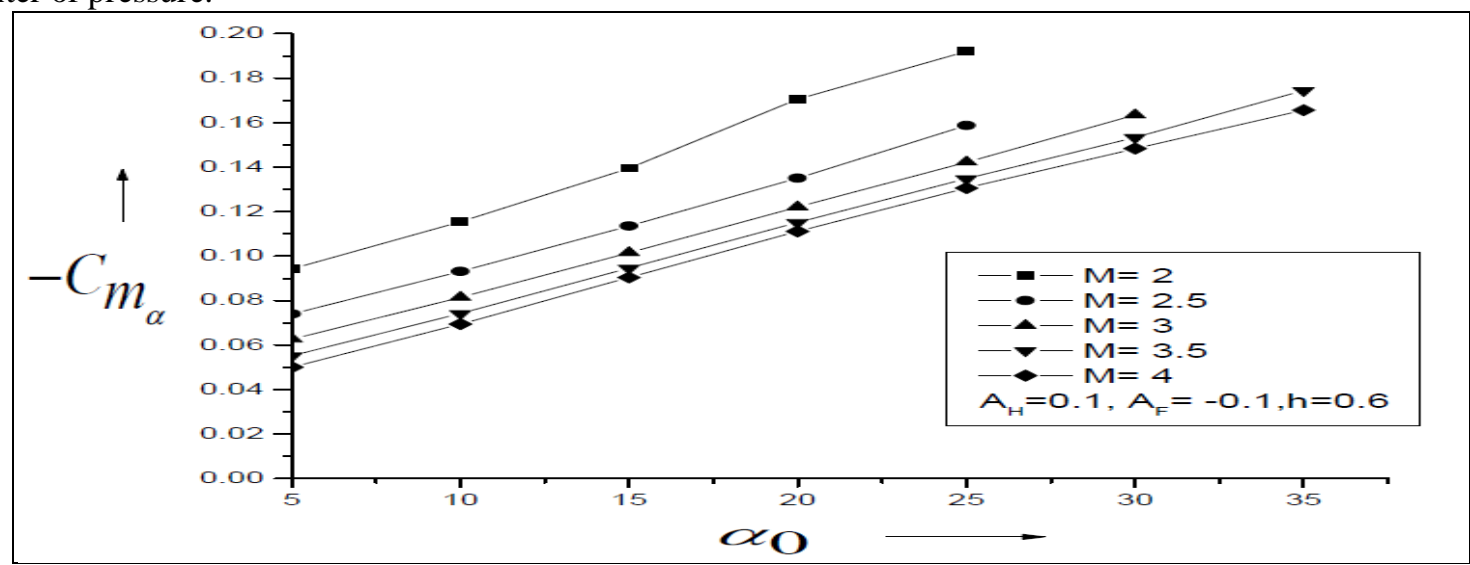

Fig. 11: Variation of Stiffness derivative with angle of attack

Fig. 11 presents the results for stiffness derivatives for full sine and half sine wave with the amplitude being -0.1 and 0.1 with the pivot position $h=0$. 6 . Here once again the results are on the similar lines as discussed earlier and there is a continuous decrease in the magnitude of the stiffness derivatives in the range of twenty one percent, thirteen percent, eleven percent and nine percent for the Mach numbers in the range 2 to 2.5 , 2.5 to 3,3 to 3.5 and 3.5 to 4 . It is seen that with the increase in the angle of attack the stiffness derivative increases linearly, nevertheless, this linear behavior is restricted for different Mach numbers. For Mach number $\mathrm{M}=2$, this limiting value of validity is fifteen degrees, for Mach $2.5 \& 3$, it is twenty five degrees, whereas, for Mach $3.5 \& 4$ it becomes thirty five degrees. The extremely low values of the stiffness derivatives are attributed due to the combined effect of variation in the wing plan form area due to the change in the amplitude of sine waves and the location of the pivot position which is in the vicinity of the center of pressure leading to the low values as a small moment arm is available. 


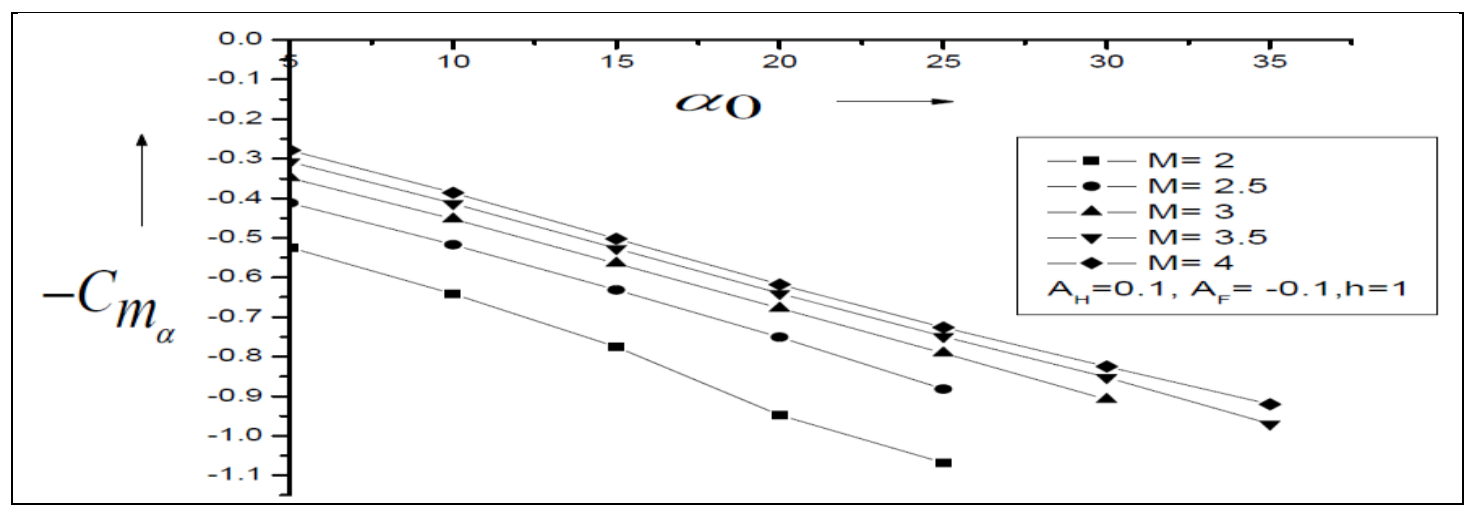

Fig. 12: Variation of Stiffness derivative with angle of attack

Fig. 12 presents the results for stiffness derivatives for full sine and half sine wave with the amplitude being -0.1 and 0.1 with the pivot position $\mathrm{h}=1.0$. From the results it is seen that they show similar results and there is a continuous decrease in the magnitude of the stiffness derivatives in the range of twenty one percent, seventeen percent, fourteen percent and seven percent for the Mach numbers in the range 2 to 2.5, 2.5 to 3, 3 to 3.5 and 3.5 to 4 . It is seen that with the increase in the angle of attack the stiffness derivative increases linearly, nevertheless, this linear behavior limit themselves for different Mach numbers. For Mach number $\mathrm{M}=2$, this limiting value of validity is fifteen degrees, for Mach 2.5 \& 3, it is twenty five degrees, whereas, for Mach 3.5 \& 4 it becomes thirty five degrees. The trend in the stiffness derivatives are attributed due to the combined effect of variation in the wing plan form area due to the change in the amplitude of sine waves and the location of the pivot position which is exactly at the trailing edge; which is behind the center of pressure.

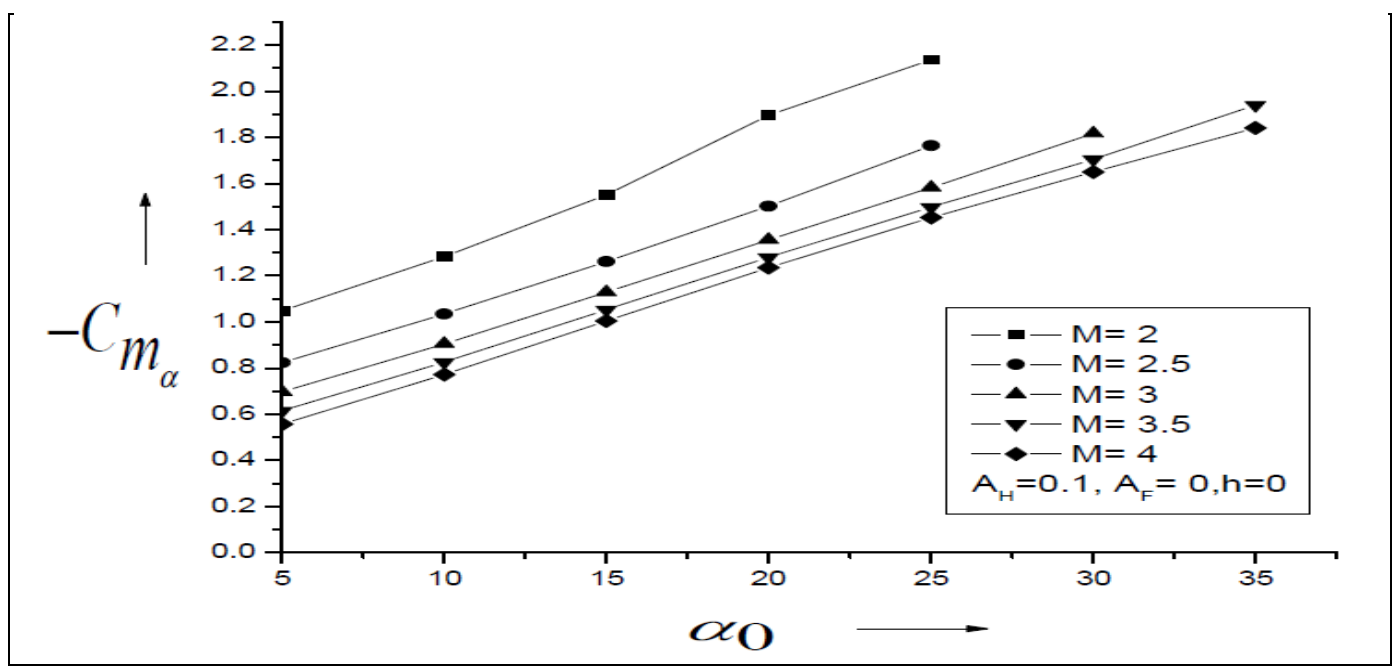

Fig. 13: variation of Stiffness derivative with angle of attack for a half sine wave

Fig. 13 presents the results for stiffness derivatives for full sine and half sine wave with the amplitude being zero and 0.1 with the pivot position $h=0$. From the results it is seen that the amplitude of full sine wave has been kept zero and that of half sine wave has been kept at the fixed value of 0.1 , it is found that there is a continuous decrease in the magnitude of the stiffness derivatives in the range of twenty three percent, fifteen percent, twelve percent and eleven percent for the Mach numbers in the range 2 to 2.5, 2.5 to 3, 3 to 3.5 and 3.5 to 4. It is seen that with the increase in the angle of attack the stiffness derivative increases linearly, nevertheless, this linear behavior limit themselves for different Mach numbers. For Mach number $\mathrm{M}=2$, this limiting value of validity is fifteen degrees, for Mach $2.5 \& 3$, it is twenty five degrees, whereas, for Mach $3.5 \&$ 4 it becomes thirty five degrees. However, inspite of pivot position being at $h=0$, the low values of the stiffness derivatives are attributed due to the combined effect of variation in the wing plan form area as in this case we have kept the amplitude of sine waves and the amplitude of full sine wave being zero resulting in the change in the shape of the wing; due to this the location of the center of pressure will also change due to the change in the pressure distribution on the surface of the wing; and also, the pivot position which is exactly at the leading edge; which is far away from the center of pressure. 


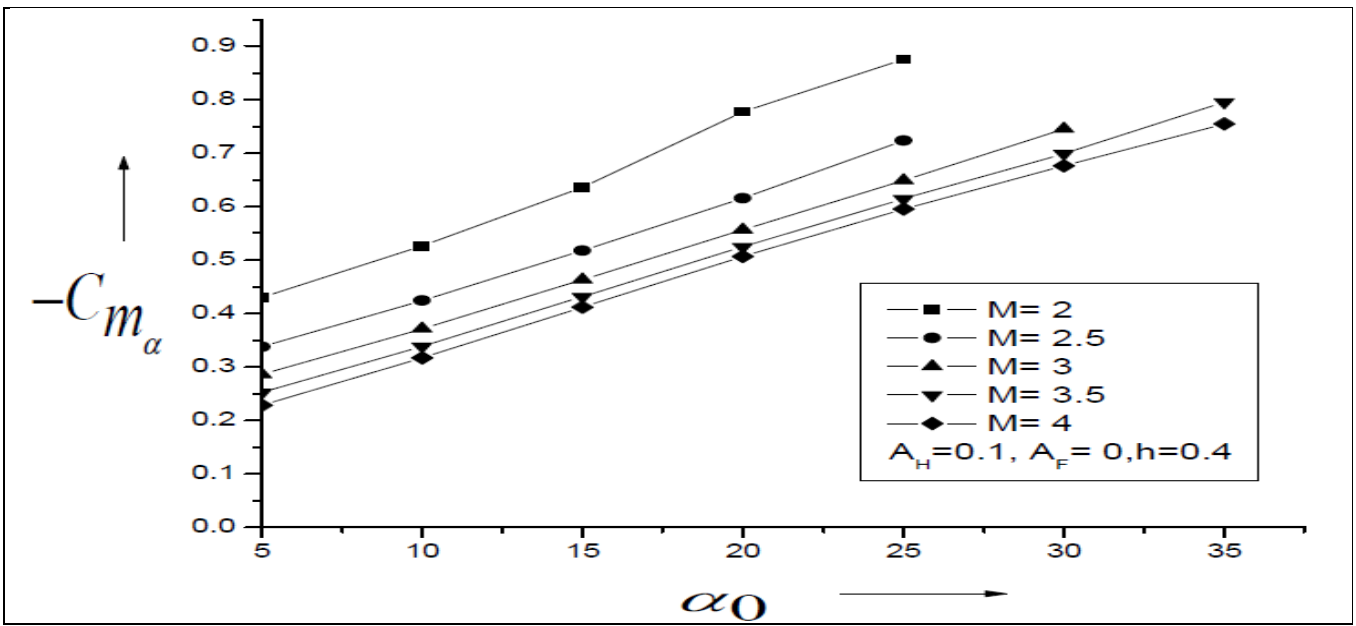

Fig. 14: Variation of Stiffness derivative with angle of attack for a half sine wave

Fig. 14 presents the results for stiffness derivatives for full sine and half sine wave with the amplitude being zero and 0.1 with the pivot position $h=0$. 4 . From the results it is seen that they present similar results leading to a continuous decrease in the magnitude of the stiffness derivatives in the range of twenty three percent, eighteen percent, fourteen percent and twelve percent for the Mach numbers in the range 2 to 2.5, 2.5 to 3,3 to 3.5 and 3.5 to 4 . It is seen that with the increase in the angle of attack the stiffness derivative increases linearly, nevertheless, this linear behavior limit themselves for different Mach numbers. For Mach number $\mathrm{M}=$ 2 , this limiting value of validity is fifteen degrees, for Mach $2.5 \& 3$, it is twenty five degrees, whereas, for Mach $3.5 \& 4$ it becomes thirty five degrees. The change in the values of the stiffness derivatives are attributed due to the combined effect of variation in the wing plan form area due to the change in the amplitude of sine waves and the location of the pivot position which forty percent aft of the leading edge; which is not far away from the center of pressure.

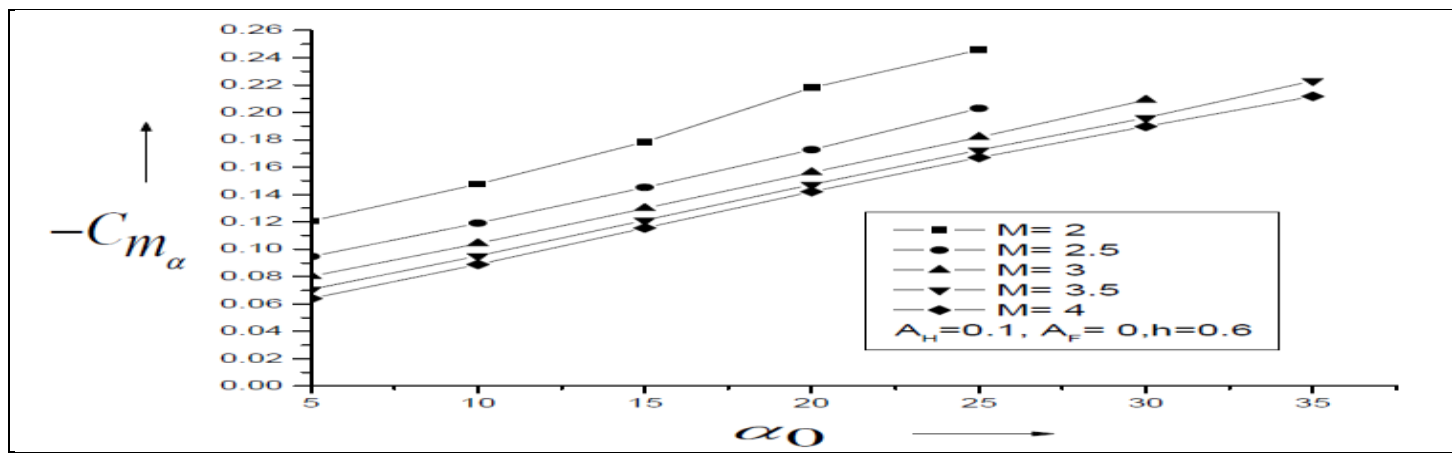

Fig. 15: Variation of Stiffness derivative with angle of attack for a half sine wave

Fig. 15 presents the results for stiffness derivatives for full sine and half sine wave with the amplitude being zero and 0.1 for a fixed pivot position $h=0$. 6. From the results it is seen that they show the similar results as discussed earlier and there is a continuous decrease in the magnitude of the stiffness derivatives in the range of twenty four percent, sixteen percent, thirteen percent and seven percent for the Mach numbers in the range 2 to $2.5,2.5$ to 3,3 to 3.5 and 3.5 to 4 . It is seen that with the increase in the angle of attack the stiffness derivative increases linearly, nevertheless, this linear behavior limit themselves for different Mach numbers as discussed earlier. The extremely low values of the stiffness derivatives are attributed due to the combined effect of variation in the wing plan form area, due to the change in the amplitude of sine waves and the location of the pivot position which is in the vicinity of the center of pressure leading to the low values because of small moment arm of the wing mean aerodynamic chord is available. 


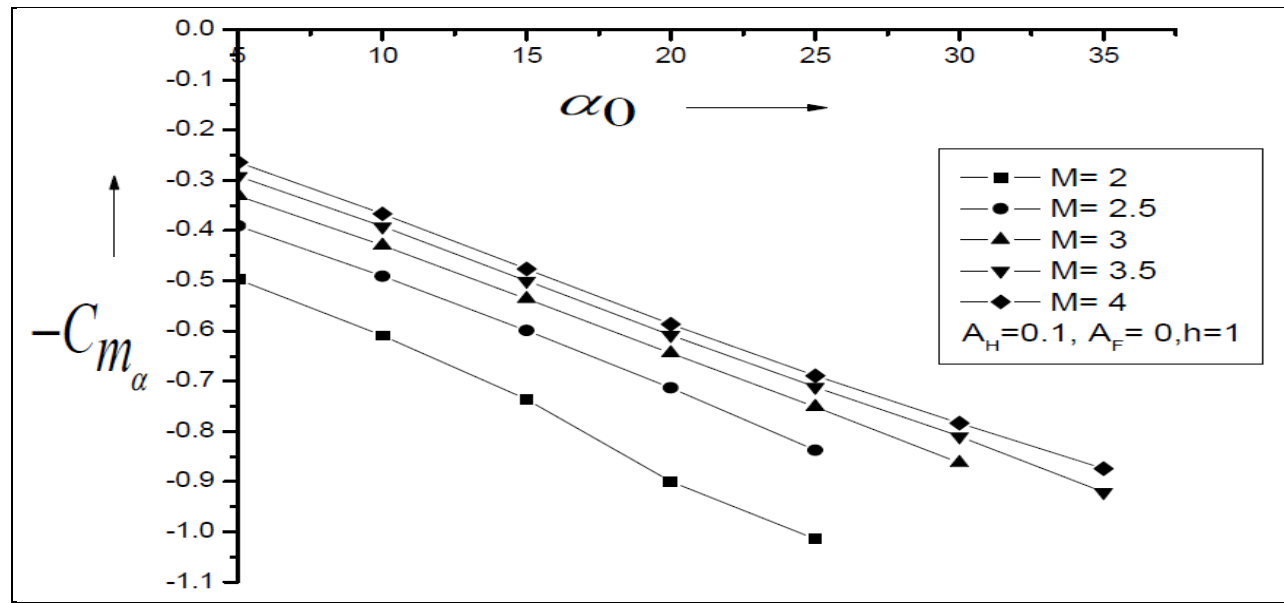

Fig. 16: Variation of Stiffness derivative with angle of attack for a half sine wave

Fig. 16 presents the results for stiffness derivatives for full sine and half sine wave with the amplitude being zero and 0.1 with the pivot position $\mathrm{h}=1.0$. From the results it is seen that they present similar results and there is a continuous decrease in the magnitude of the stiffness derivatives in the range of twenty percent, eighteen percent, fifteen percent and ten percent for the Mach numbers in the range 2 to 2.5, 2.5 to 3,3 to 3.5 and 3.5 to 4 . It is seen that with the increase in the angle of attack the stiffness derivative increases linearly, nevertheless, this linear behavior limit themselves for different Mach numbers. For Mach number $\mathrm{M}=2$, this limiting value of validity is fifteen degrees, for Mach $2.5 \& 3$, it is twenty five degrees, whereas, for Mach $3.5 \&$ 4 it becomes thirty five degrees. This trend of the stiffness derivatives are attributed due to the combined effect of variation in the wing plan form area due to the change in the amplitude of sine waves and the location of the pivot position which is exactly at the trailing edge; which is behind the center of pressure.

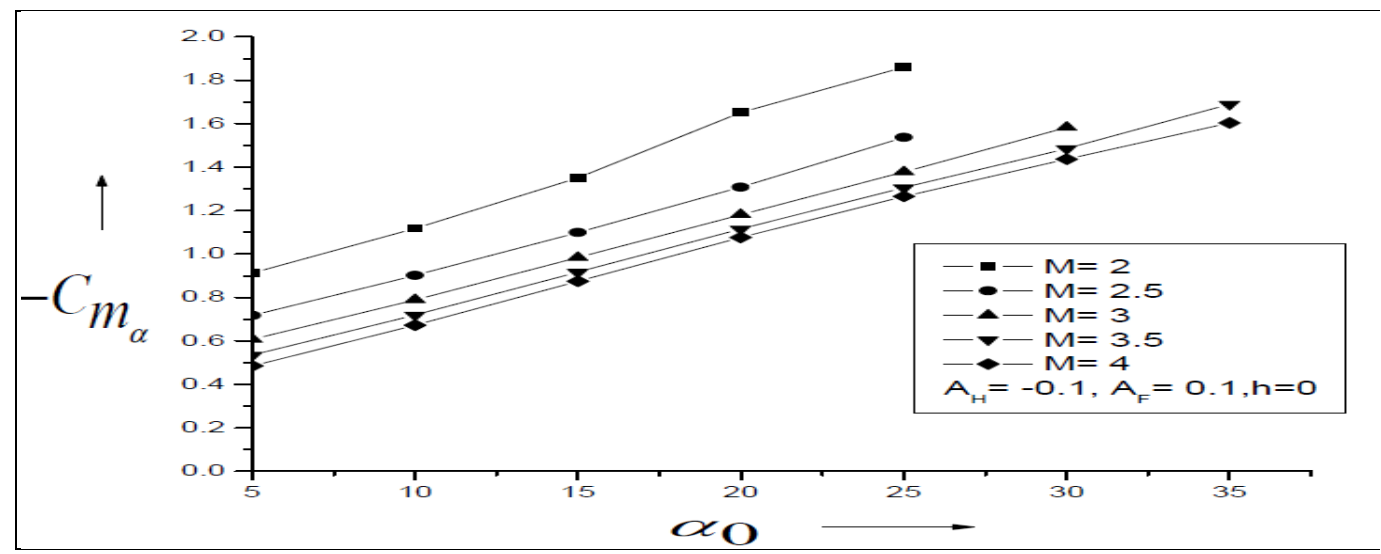

Fig. 17: Variation of Stiffness derivative with angle of attack

Fig. 17 presents the results for stiffness derivatives for full sine and half sine wave with the amplitude being 0.1 and -0.1 with the pivot position $h=0$. From the results it is seen that the amplitude of full sine wave has been kept at a value of 0.1 and half sine wave has been kept to a fixed value of -0.1 , it also observed that there is a continuous decrease in the magnitude of the stiffness derivatives in the range of twenty two percent, eighteen percent, thirteen percent and eight percent for the Mach numbers in the range 2 to $2.5,2.5$ to 3,3 to 3.5 and 3.5 to 4 . It is seen that with the increase in the angle of attack the stiffness derivative increases linearly, nevertheless, this linear behavior limit themselves for different Mach numbers. For Mach number $\mathrm{M}=2$, and this limiting value of validity is fifteen degrees, for Mach $2.5 \& 3$, it is twenty five degrees, whereas, for Mach $3.5 \& 4$ it becomes thirty five degrees. This trend may be due to the combined effect of variation in the wing plan form area due to the sign change in the amplitude of half sine wave and the amplitude of full sine wave being 0.1 and due to this change in the shape of the wing as the amplitude of the full sine wave is kept constant at 0.1 ; whereas, the location of the center of pressure will also change due to the change in the pressure distribution on the surface of the wing; and also, the pivot position which is exactly at the leading edge; which is far away from the center of pressure. 


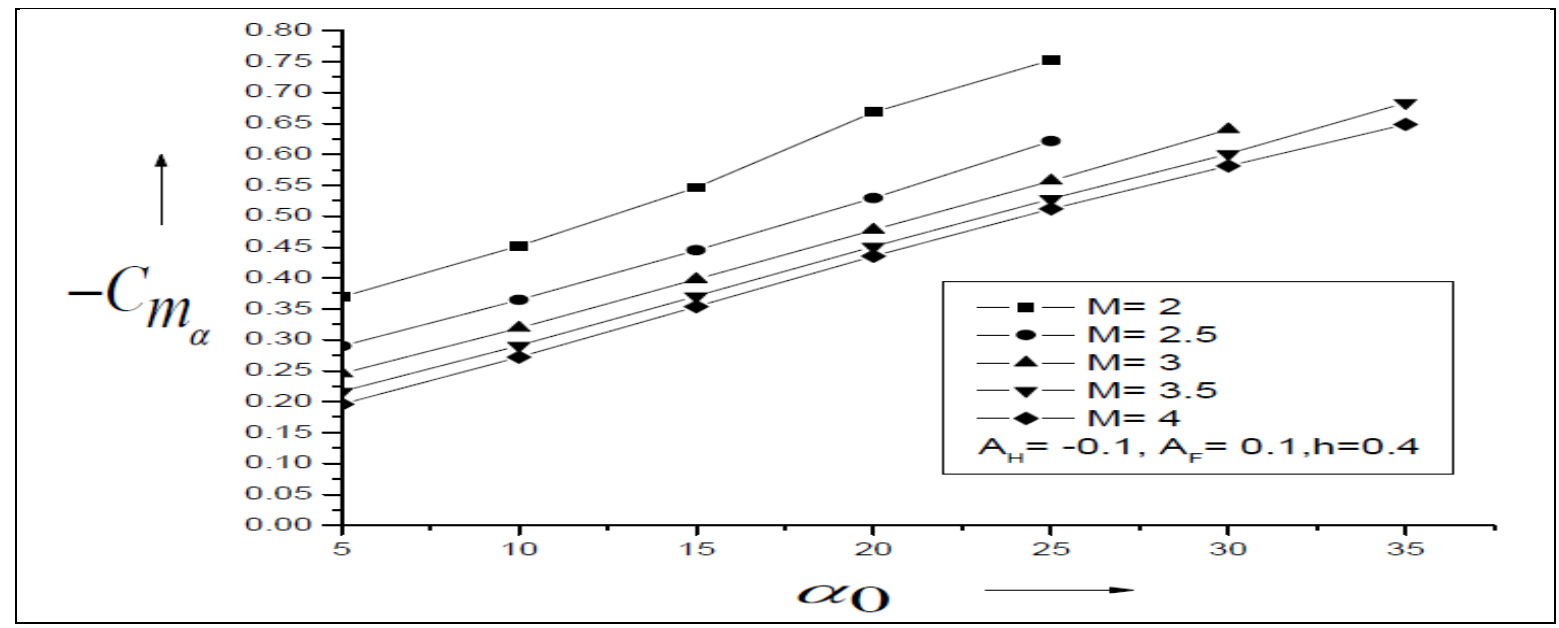

Fig. 18: Variation of Stiffness derivative with angle of attack

Fig. 18 presents the results for stiffness derivatives for full sine and half sine wave with the amplitude being 0.1 and -0.1 with the pivot position $h=0.4$. From the results it is seen that they represent similar results and there is a continuous decrease in the magnitude of the stiffness derivatives in the range of twenty three percent, fourteen percent, twelve percent and ten percent for the Mach numbers in the range 2 to 2.5, 2.5 to 3, 3 to 3.5 and 3.5 to 4 . It is seen that with the increase in the angle of attack the stiffness derivative increases linearly, nevertheless, this linear behavior limit themselves for different Mach numbers. For Mach number $\mathbf{M =}$ 2 , this limiting value of validity is fifteen degrees, for Mach $2.5 \& 3$, it is twenty five degrees, whereas, for Mach $3.5 \& 4$ it becomes thirty five degrees. These low values of the stiffness derivatives are attributed due to the combined effect of variation in the wing plan form area due to the sign change in the amplitude of half sine wave and the amplitude of full sine wave kept constant at 0.1 ; whereas, the location of the pivot position which is forty percent aft of the leading edge; also happen to be in the close proximity of the center of pressure.

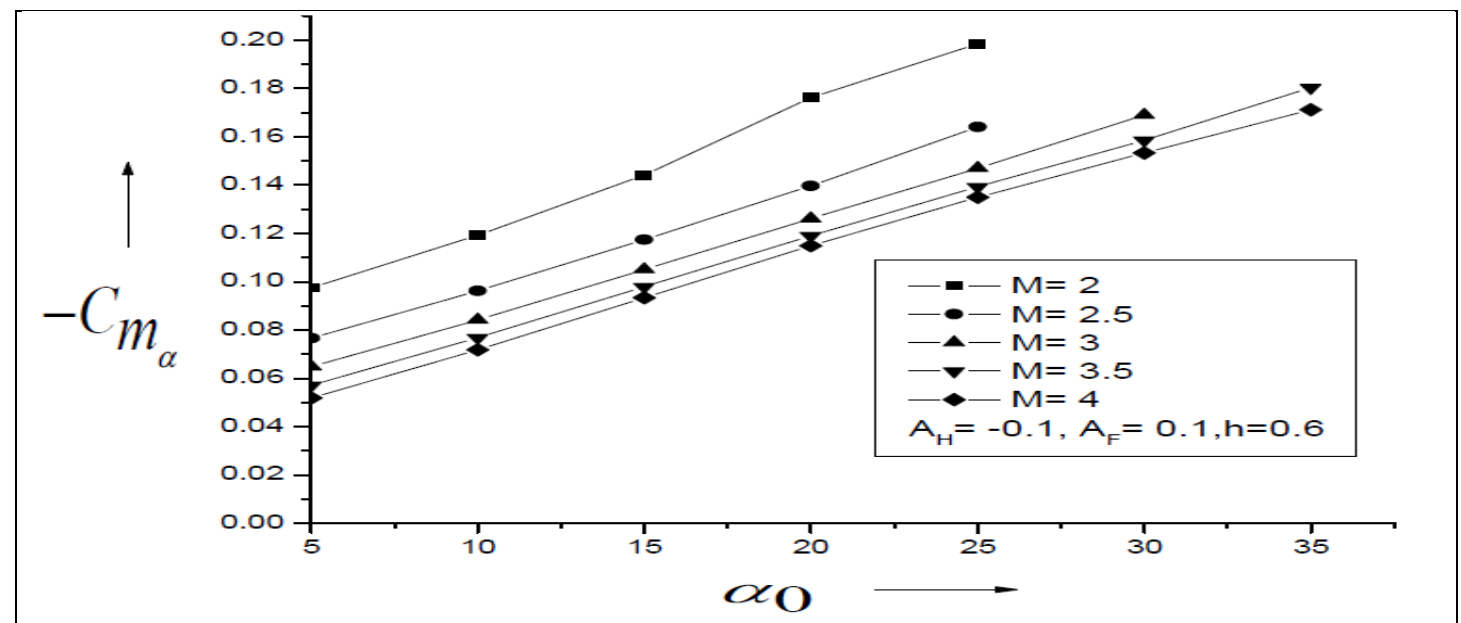

Fig. 19: Variation of Stiffness derivative with angle of attack

Fig. 19 presents the results for stiffness derivatives for full sine and half sine wave with the amplitude being -0.1 and 0.1 with the pivot position $h=0.6$. From the results it is seen that they show the similar results as discussed earlier and there is a continuous decrease in the magnitude of the stiffness derivatives in the range of nineteen percent, seventeen percent, twelve percent and ten percent for the Mach numbers in the range 2 to 2.5, 2.5 to 3,3 to 3.5 and 3.5 to 4 . It is seen that with the increase in the angle of attack the stiffness derivative increases linearly, nevertheless, this linear behavior limit themselves for different Mach numbers. For Mach number $\mathrm{M}=2$, this limiting value of validity is fifteen degrees, for Mach $2.5 \& 3$, it is twenty five degrees, whereas, for Mach $3.5 \& 4$ it becomes thirty five degrees. The extremely low values of the stiffness derivatives are attributed due to the combined effect of variation in the wing plan form area due to the change in the amplitude of sine waves and the location of the pivot position which is in the vicinity of the center of pressure leading to the low values because of small moment arm available. 


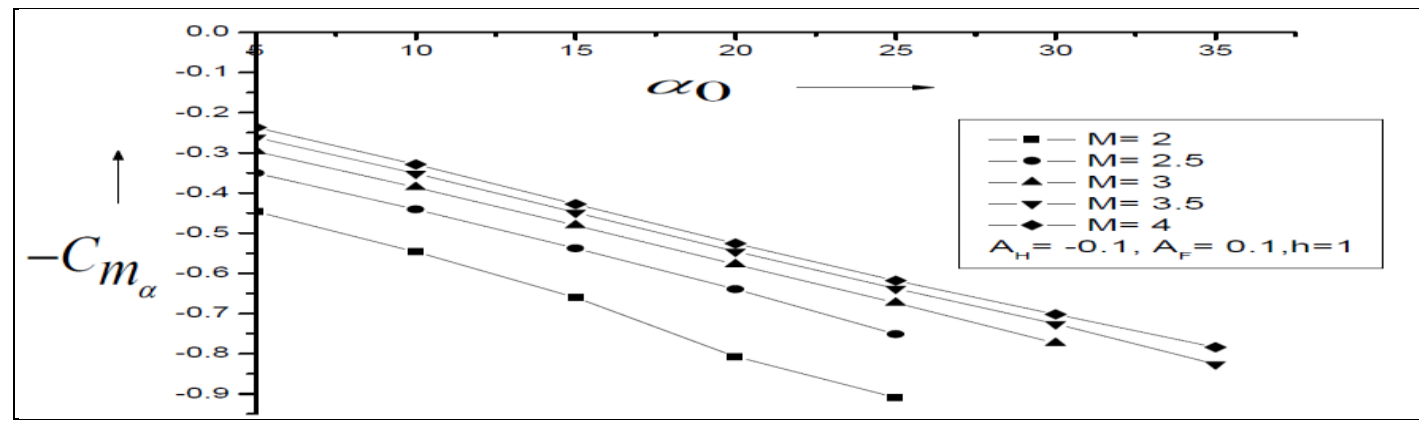

Fig. 20: Variation of Stiffness derivative with angle of attack

Fig. 20 presents the results for stiffness derivatives for full sine and half sine wave with the amplitude being 0.1 and -0.1 with the pivot position $h=1.0$. From the results it is seen that they depict similar results and there is a continuous decrease in the magnitude of the stiffness derivatives in the range of twenty two percent, fifteen percent, thirteen percent and ten percent for the Mach numbers in the range 2 to $2.5,2.5$ to 3,3 to 3.5 and 3.5 to 4 . It is seen that with the increase in the angle of attack the stiffness derivative increases linearly, nevertheless, this linear behavior limit themselves for different Mach numbers. For Mach number $\mathrm{M}=2$, this limiting value of validity is fifteen degrees, for Mach 2.5 \& 3, it is twenty five degrees, whereas, for Mach 3.5 \& 4 it becomes thirty five degrees. The extremely low values of the stiffness derivatives are attributed due to the combined effect of variation in the wing plan form area due to the change in the amplitude of sine waves and the location of the pivot position which is exactly at the trailing edge; which is behind the center of pressure.

\section{Conclusions:}

From above discussions we can draw the following conclusions;

- It is observed that the magnitude of the stiffness derivative is continuously decreasing with the increase in the Mach number for all the Mach number in the range from $M=2$ to 4 .

- It is also observed that when we change the pivot position from $\mathrm{h}=0,0.4,0.6$, and 1 , the stiffness derivative decreases throughout for the present range of Mach numbers, wing plan form area and the pivot position.

- It is seen that with the increase in the angle of attack the stiffness derivative increases linearly, nevertheless, this linear behavior limit themselves for different Mach numbers. For Mach number $\mathrm{M}=2$, this limiting value of validity is fifteen degrees, for Mach $2.5 \& 3$, it is twenty five degrees, whereas, for Mach $3.5 \& 4$ it becomes thirty five degrees.

- Whenever, the amplitude of the full and half sine wave was varied from \pm 1 and \pm 2 ; which results in change in the shape of the wing. The convexity in the shape of the wing results in increase of the stiffness derivative and reverse is observed when the wing leading edge is concave.

- Results have been obtained for supersonic flow of perfect gases over a wide range of angle of attack, various plan form geometry of the wing and the Mach numbers in the range from 2 to 4 . The effect of real gas, leading edge bluntness of the wing, shock motion, and secondary wave reflections are neglected.

\section{References:}

[1]. Pike. J, "The pressure on flat and anhydral delta wings with attached shock waves", The Aeronautical Quarterly, November 1972, XXIII, Part 4, pp. 253-262.

[2]. Hui, W.H., "Stability of Oscillating Wedges and Caret Wings in Hypersonic and Supersonic Flows", AIAA Journal, Vol. 7, Aug. 1969, pp.1524-1530.

[3]. Carrier, G.F. 1949, “The oscillating Wedge in Supersonic stream”, Journal of Aeronautical Sciences, Vol. 16, No. 3, pp. 150-152, March.

[4]. Hui, W. H., "Supersonic/hypersonic flow past on oscillating flat plate at high angles of attack", ZAMP, Vol. 29, 1978, pp. 414-427.

[5]. Hui, W. H., "Supersonic and hypersonic flow with attached shock waves over delta wings", Proc of Royal Society, London, 1971, A. 325 , pp. 251-268.

[6]. Orlik-Ruckemann, K. J., "Dynamic stability testing of aircraft needs versus capabilities", Progress in the Aerospace Sciences, Academic press, N.Y., 1975, 16, pp. 431-447.

[7]. Hui, W. H. and Hemdan, H. T., "Unsteady hypersonic flow over delta wings with detached shock waves", AIAA Journal, April 1976,14 , pp. 505-511.

[8]. Lui, D. D. and Hui W. H., "Oscillating delta wings with attached shock waves," AIAA Journal”, June 1977, 15, 6, pp. 804-812.

[9]. Light Hill, M. J., "Oscillating Aerofoil at High Mach Numbers”, Journal of Aeronautical Sciences, Vol. 20 , June 1953, pp. $402-406$.

[10]. Ghosh K, "A new similitude for aerofoil in hypersonic flow", Proc of the 6th Canadian congress of applied mechanics", Vancouver, $29^{\text {th }}$ May $3^{\text {rd }}$ June, 1977 , pp. 685-686.

[11]. Miles, J. W., "Unsteady flow at hypersonic speeds, Hypersonic flow”, Butter worths Scientific Publications, London, 1960, pp. 185197.

[12]. Ghosh, K and Mistry B. K., "Large incidence hypersonic similitude and oscillating non-planar wedges", AIAA Journal, August $1980,18,8$, pp. 1004-1006. 
[13]. Ghosh K., "Hypersonic large deflection similitude for oscillating delta wings", The Aeronautical journal, October, 1984, pp. 357361.

[14]. Asha Crasta and Khan S. A., "High Incidence Supersonic similitude for Planar wedge", International Journal of Engineering research and Applications, Vol. 2, Issue 5, September-October 2012, pp. 468-471.

[15]. Khan S. A. and Asha Crasta, "Oscillating Supersonic delta wings with curved leading edges", Advanced Studies in Contemporary mathematics, Vol. 20 (2010), No.3, pp. 359-372.

[16]. Asha Crasta and S. A. Khan, "Estimation of Stability derivatives of an Oscillating Hypersonic delta wings with curved leading edges",Vol.3, Issue 3, December 2012, pp. 483-492.,

[17]. Asha Crasta and S. A. Khan, "Effect of Angle of Incidence on Stability derivatives of a wing", International Journal for Research in Applied Science and Engineering Technology, Vol. 2, Issue V, May 2014, pp. 411-422.

[18]. Asha Crasta and S. A. Khan, "Hypersonic Similitude for Planar Wedges", International Journal of Advanced Research in Engineering and Technology, Volume 5, Issue2, February 2014, pp. 16-31.

[19]. Asha Crasta and S. A. Khan, "Estimation of Stability Derivatives for a Planar Wedge in the Newtonian Limit", IOSR Journal of Mathematics, Volume 10, Issue 2, Version I, March-April 2014, pp. 01-06.

[20]. Asha Crasta and S. A. Khan, "Effect of Mach number on Stiffness and Damping Derivatives for Oscillating Hypersonic Non-Planar Wedge", IOSR Journal of Mechanical and Civil Engineering, Volume 11, Issue 2, Ver. VIII, March- April 2014 , pp. 04-11.

[21]. Asha Crasta and S. A. Khan,"Effect of Angle of Incidence on Stiffness and Damping derivatives for Oscillating Hypersonic Nonplanar Wedge", International Journal for Research in Applied Science and Engineering Technology, Vol. 2, Issue IV, April 2014, pp. 229-242.

[22]. Asha Crasta and S. A. Khan, "Supersonic Similitude for Oscillating Non-Planar wedge", IOSR Journal of Mathematics, Volume 10, Issue 2, Ver.VI, March-April 2014, pp.15-24.

[23]. Asha Crasta, M. A. Baig, S. A. Khan , 'Estimation of Stability derivatives of a Delta wing in Hypersonic flow', International Journal of Emerging trends in Engineering and Developments, Vol. 6, Issue 2, September 2012, pp. 505-516.

[24]. Asha Crasta and S. A. Khan, "Oscillating Supersonic delta wing with Straight Leading Edges", International Journal of Computational Engineering Research, Vol. 2, Issue 5, September 2012, pp. 1226-1233.

[25]. Asha Crasta and S. A. Khan, 'Stability derivatives of a Delta Wing with Straight leading edge in the Newtonian Limit', International Journal of Engineering research and Applications, Vol. 4, Issue 3, Version 2, March 2014, pp. 32 -38.

[26]. Asha Crasta and S. A. Khan, "Stability Derivatives in the Newtonian Limit", International Journal of Advanced Research in Engineering and Technology, Volume 4, Issue 7, November-December 2013, pp. 276-289.

[27]. Asha Crasta, S. A. Khan, 'Effect of angle of incidence on Roll damping derivative of a Delta Wing', International Journal of Emerging trends in Engineering and Developments Volume 2, Issue 4, March 2014, pp. 343-356.

[28]. Asha Crasta, S.A.Khan, 'Effect of sweep angle on Roll damping derivative of a Delta Wing', International Journal of Emerging trends in Engineering and Developments Volume 5, Issue 4, August-September 2014, pp. 45-55.

[29]. Asha Crasta and S.A. Khan, 2014, 'Effect of Angle of Incidence on Stability derivatives of a wing', International Journal for Research in Applied Science and Engineering Technology, Vol. 2, Issue V, May, pp. 411-422.

[30]. Asha Crasta and S.A. Khan, 2014 ,'Effect of Angle of attack on Stability derivatives of a Delta wing with Straight leading edge in Supersonic Flow',International Journal of Mathematics, Vol.10,issue5,Sep-oct 2014. Pp. 01-08,

[31]. Asha Crasta and S.A.Khan, 2014,' Effect of Angle of attack on Stability Derivatives of a Delta wing in Hypersonic Flow with Straight leading edge',International Journal of Mechanical and civil enginering, Volume 11, Issue 5 Ver. II (Sep- Oct. 2014), PP 2129. 